\title{
Jurnal

\section{Persepsi Pengunjung Tentang Sarana di Daya Tarik Wisata Taman Wisata Alam Rimbo Panti Kabupaten Pasaman}

\author{
Suci Trisnani, Kurnia Illahi Manvi ${ }^{2}$ \\ ${ }^{1}$ Universitas Negeri Padang \\ ${ }^{2}$ Universitas Negeri Padang
}

Corresponding email : sucitrisnani16@gmail.com

\begin{abstract}
ABSTRAK
Penelitian ini berawal dari permasalahan yang timbul di daya Tarik Wisata Taman Wisata Alam (TWA) Rimbo Panti seperti belum adanya petunjuk arah khusus area parkir sehingga wisatawaan memarkirkan kendaraannya sembarangan, bangunan mushalla yang sudah rusak, tidak adanya petunjuk arah antara toilet wanita dan laki-laki, tidak optimalnya tempat sampah di daya tarik TWA Rimbo Panti dan toilet yang banyak ditumbuhi lumut. Penelitian mengunakan metode deskriptif kuantitatif dengan metode survei. Pengumpulan data dengan kuesioner dan skala likert. Populasi pada penelitian ini yaitu pengunjung yang datang ke daya tarik TWA Rimbo Panti. Teknik pengambilan sampel yaitu non probability sampling dengan metode incidental sampling, dengan jumlah 100 responden. Hasil penelitian yang telah dilakukan menunjukan bahwa persepsi pengunjung tentang sarana di daya tarik TWA Rimbo Panti menunjukkan kategori cukup baik sebanyak 53\% dengan rentang skor 52,6 - <73,33. (1) berlandaskan indikator Bentuk Sarana dikategorikan baik dengan persentase $34 \%$ yang berada pada rentang skor 16,665 - < 19,995. (2) berlandaskan indikator Fungsi Sarana dikategorikan cukup baik dengan persentase $37 \%$ yang berada pada rentang skor $16-<20$. (3) berlandaskan indikator Lokasi Sarana dikategorikan baik dengan persentase $37 \%$ yang berada pada rentang skor 16,665 - < 19,995. (4) berlandaskan indikator Mutu Sarana dikategorikan cukup baik dengan persentase $39 \%$ yang berada pada rentang skor 13,355 $-<16,665$.
\end{abstract}

Kata kunci : Persepsi, Pengunjung, Sarana, Daya Tarik Wisata 


\section{PENDAHULUAN}

"Pariwisata merupakan berbagai macam kegiatan wisata yang didukung dengan berbagai fasilitas serta layanan yang disediakan oleh masyarakat, pengusaha, Pemerintah, dan Pemerintah Daerah" [1]. Salah satu sektor industri penting bagi Indonesia adalah pariwisata, karna dengan adanya industri pariwisata, dapat meningkatkan pendapatan bagi pemerintah serta masyarakat disekitar objek wisata. Indonesia mempunyai potensi wisata yang sangat menjajikan untuk dikembangkan, sebab Indonesia merupakan negara kepulauan yang mempunyai beragam budaya, suku bangsa, serta kekayaaan alam yang melimpah. Salah satu provinsi di Indonesia yang memiliki potensi wisata alam yang indah dan menarik adalah Sumatera Barat. Hal ini didukung dengan wilayah dengan keindahan panorama alamnya, keunikan adat istiadatnya, ragam kuliner, kesenian dan situs-situs bersejarah yang dimilikinya.

Kabupaten Pasaman memiliki potensi wisata alamnya yang unik dan menarik seperti, Air Terjun Sarasah dan Wisata Cagar Alam. Cagar alam ialah kawasan suaka alam yang keadaan alamnya memiliki kekhasan tumbuhan, satwa, dan ekosistemnya atau ekosistem tertentu yang perlu dilindungi dan perkembangannya berlangsung secara alami [2]. Salah satu daya tarik wisata cagar alam yang berada di Kabupaten Pasaman yaitu Taman Wisata Alam (TWA) Rimbo Panti. Daya tarik wisata ini memiliki keindahan cagar alam dan sumber air panas yang terletak di Panti Nagari Panti, Kecamatan Panti, Kabupaten Pasaman, Provinsi Sumatera Barat.

Wilayah di daya tarik wisata TWA Rimbo Panti terdapat kolam pemandian air panas yang berada di daya tarik wisata. TWA Rimbo Panti ini sering dikunjungi pada saat liburan sekolah dan pada hari Hari Raya Idul Fitri dan Perayaan Natal. Faktor utama yang menjadi dasar pengunjung datang ke sebuah daya tarik wisata bukan hanya dari kualitas daya tarik wisatanya saja, tetapi juga dinilai dari sarananya seperti bentuk sarana, fungsi sarana, lokasi sarana dan mutu sarana dari daya tarik wisata tersebut. "Sarana Pariwisata merupakan segala fasilitas yang disediakan daerah tujuan wisata yang diperlukan untuk melayani kebutuhan wisatawan dalam menikmati perjalanan wisatanya yaitu terdiri dari perusahaanperusahaan yang memberikan pelayanan kepada wisatawan, baik secara langsung maupun secara tidak langsung dan kehidupannya bergantung pada kedatangan wisatawan” [3].

Dari hasil pra observasi peneliti, peneliti menemukan beberapa masalah dari pengunjung yang datang ke TWA Rimbo Panti yaitu Tempat ibadah di daya tarik TWA Rimbo Panti yang sudah tidak bisa digunakan lagi karena telah ditumbuhi lumut, Toilet di TWA Rimbo Panti yang kurang bersih karena telah ditumbuhi lumut dan juga rerumputan liar disekitarnya, Tidak adanya tempat sampah di TWA Rimbo Panti, sehingga sampah berserakan. Tempat parkir yang belum teratur, sehingga pengunjung memarkirkan kendaraannya sembarangan.

Sehingga dalam mengembangkan daya Tarik wisata wisata TWA Rimbo Panti dibutuhkan persepsi atau pandangan pengunjung tentang sarana, sebagai informasi bagi pengelola daya tarik atau pemerintah dalam pengembangan sebuah daya tarik wisata. Persepsi merupakan proses bagaimana seorang individu memilih, mengorganisasikan dan menginterprestasikan masukan informasi untuk menciptakan pandangan atau pendapat yang memiliki arti [4]. Sebab pandangan atau penilaian pengunjung juga sangat mempengaruhi keberlajutan jangka panjang sebuah daya tarik wisata pada daerah tesebut agar pengembangan daya tarik wisata tersebut menjadi lebih baik. Adapun sasaran penelitian ini untuk mengetahui persepsi pengunjung yang ditinjau dari Bentuk Sarana, Fungsi Sarana, Lokasi Sarana dan Mutu Sarana.

\section{METODOLOGI}

Penelitian ini merupakan penelitian deskriptif kuantitatif. Data yang digunakan merupakan data primer dan data sekunder. Populasi pada penelitian ini yaitu pengunjung yang berkunjung ke daya Tarik wisata TWA Rimbo Panti Kabupaten Pasaman, dengan sampel 100 responden. Teknik sampling yang digunakan dalam penelitian ini adalah non probability sampling, yaitu teknik pengambilan sampel yang 
tidak memberikan peluang yang sama atau setara bagi setiap anggota populasi untuk dipilih menjadi sampel [5]. Jenis non probability sampling yang digunakan yaitu insidental Sampling adalah teknik penentuan sampel secara kebetulan. Penelitian ini mengunakan analisis deskriptif, mengunakan pengolahan metabulasi data dan deskritif data yang mengklasifikasikan skor kedalam 5 kategori untuk melihat tingkat pencapaian responden.

\section{HASIL DAN PEMBAHASAN}

\section{A. Hasil Penelitian}

\section{a. Deskripsi Karateristik Responden}

berlandaskan hasil penelitian yang telah dilakukan mengenai persepsi pengunjung tentang sarana di daya tarik TWA Rimbo Panti, berupa kuesioner yang disusun dalam bentuk peryataan yang telah dilakukan uji validitas serta reabilitasnya yang kemudian di sebarkan ke 100 responden untuk diberi jawaban. Jumlah pernyataan yang diberikan kepada responden adalah sebanyak 21 peryataan, maka responden pada penelitian ini dapat digolongkan ke dalam beberapa karateristik yaitu sebagai berikut :

Kerakteristik responden berlandaskan jenis kelamin di peroleh informasi bahwa mayoritas responden pada penelitian ini ialah perempuan sebanayak 53\%, mayoritas responden pada penellitian ini berusia 20-25 tahun dengan persentase sebanyak $46 \%$, untuk responden berlandaskan pekerjaannya di peroleh hasil bahwa mayoritas responden pada penelitian ini yaitu yang bekerja sebagai Pelajar/Mahasiswa dengan persentase sebanyak 44\%, dan kerakteristik responden berlandaskan jumlah kunjungannya di peroleh informasi bahwa mayoritas responden pada penelitian ini yaitu lebih dari 4 kali kunjungan dengan persentase sebanyak $83 \%$.

\section{b. Deskripsi Data Variabel Penelitian Daya Tarik Wisata Taman Wisata Alam Rimbo Panti}

Hasil dari pengolahan data perhitungan statistik mengenai persepsi pengunjung tentang sarana di daya tarik wisata TWA Rimbo Panti di Kabupaten Pasaman terdapat pad tabel 1 berikut :

\section{Tabel 1. Deskripsi Variabel Persepsi Pengunjung Tentang Sarana di Daya Tarik Wisata} Taman Wisata Alam Rimbo Panti

\begin{tabular}{|c|c|c|c|}
\hline Kategori & Rentang Skor & F & \% \\
\hline Sangat Baik & $\geq 93,99$ & 1 & $1 \%$ \\
\hline Baik & $73,33-<93,99$ & 6 & $6 \%$ \\
\hline Cukup Baik & $52,67-<73,33$ & 53 & $53 \%$ \\
\hline Buruk & $32,01-<52,67$ & 27 & $27 \%$ \\
\hline Sangat Buruk & $<32,01$ & 13 & $13 \%$ \\
\hline \multicolumn{2}{|r|}{ Jumlah } & $\mathbf{1 0 0}$ & $\mathbf{1 0 0 \%}$ \\
\hline
\end{tabular}

Dari hasil dari tabel diatas dapat dijelaskan bahwa: 1\% menunjukan kategori sangat baik, $6 \%$ menunjukan kategori baik, 53\% menunjukan kategori cukup baik, 27\% menunjukan kategori buruk dan 13\% menunjukan kategori sangat buruk. Maka kesimpulanya persepsi pengunjung tentang sarana di TWA Rimbo Panti Kabupaten Pasaman dikategorikan cukup baik. Selanjutnya hasil uji deskripsi berlandaskan ke empat indikator yaitu indikator bentuk sarana, fungsi sarana, lokasi sarana dan mutu sarana. Maka didapatkan diuraikan hasilnya sebagai berikut : 


\section{1) Deskripsi Indikator Bentuk Sarana}

Berikut berlandaskan hasil pengolahan data statistik dapat dilihat pada tabel 2:

Tabel 2. Deskripsi Indikator Bentuk Sarana

\begin{tabular}{|c|c|c|c|}
\hline Kategori & Rentang Skor & F & \% \\
\hline Sangat Baik & $\geq 19,995$ & 18 & $18 \%$ \\
\hline Baik & $16,665-<19,995$ & 34 & $34 \%$ \\
\hline Cukup Baik & $13,355-<16,665$ & 14 & $14 \%$ \\
\hline Buruk & $10,005-<13,335$ & 10 & $10 \%$ \\
\hline Sangat Buruk & $<10,005$ & 24 & $24 \%$ \\
\hline \multicolumn{2}{|r|}{ Jumlah } & $\mathbf{1 0 0}$ & $\mathbf{1 0 0 \%}$ \\
\hline
\end{tabular}

Dari tabel diatas dapat diketahui bahwa dari 100 responden untuk indikator bentuk sarana dapat dikategorikan sebagai berikut : kategori sangat baik menunjukan persentase sebanyak $18 \%$, kategori baik menunjukan persentase sebanyak $34 \%$, kategori cukup baik menunjukan sebanyak $14 \%$, kategori buruk menunjukan sebanyak $24 \%$, dan kategori sangat buruk menunjukan $24 \%$. Sehingga dapat disimpulkan bahwa persepsi pengunjung tentang bentuk sarana di TWA Rimbo Panti dikategorikan baik.

\section{2) Deskripsi Indikator Fungsi Sarana}

Berikut berlandaskan hasil pengolahan data statistik dapat dilihat pada tabel 3 :

Tabel 3 . Deskripsi Indikator Fungsi Sarana

\begin{tabular}{|c|c|c|c|}
\hline Kategori & Rentang Skor & F & \% \\
\hline Sangat Baik & $\geq 24$ & 1 & $1 \%$ \\
\hline Baik & $20-<24$ & 15 & $15 \%$ \\
\hline Cukup Baik & $16-<20$ & 37 & $37 \%$ \\
\hline Buruk & $12-<16$ & 17 & $17 \%$ \\
\hline Sangat Buruk & $<12$ & 30 & $30 \%$ \\
\hline \multicolumn{2}{|c|}{ Jumlah } & $\mathbf{1 0 0}$ & $\mathbf{1 0 0 \%}$ \\
\hline
\end{tabular}

Dari tabel diatas dijelaskan bahwa persepsi pengunjung tentang fungsi sarana dapat dikategorikan sebagai berikut: kategori sangat baik menunjukan persentase sebanyak 1\%, kategori baik menunjukan persentase sebanyak 15\%, kategori cukup baik menunjukan sebanyak 37\%, kategori buruk menunjukan sebanyak 17\%, dan kategori sangat buruk menunjukan $30 \%$. Sehingga dapat disimpulkan bahwa pandangan atau persepsi pengunjung tentang fungsi sarana di kategorikan cukup baik.

\section{3) Deskripsi Indikator Lokasi Sarana}

Berikut berlandaskan hasil pengolahan data statistik dapat dilihat pada tabel 4 :

Tabel 4. Deskripsi Indikator Lokasi Sarana

\begin{tabular}{|c|c|c|c|}
\hline Kategori & Rentang Skor & F & \% \\
\hline Sangat Baik & $\geq 19,995$ & 6 & $6 \%$ \\
\hline Baik & $16,665-<19,995$ & 37 & $37 \%$ \\
\hline Cukup Baik & $13,355-<16,665$ & 17 & $17 \%$ \\
\hline Buruk & $10,005-<13,335$ & 13 & $13 \%$ \\
\hline Sangat Buruk & $<10,005$ & 27 & $27 \%$ \\
\hline \multicolumn{2}{|r|}{ Jumlah } & $\mathbf{1 0 0}$ & $\mathbf{1 0 0 \%}$ \\
\hline
\end{tabular}


Dari hasil pada tabel diatas dijelaskan bahwa persepsi pengunjung tentang lokasi sarana dapat dikategorikan sebagai berikut: kategori sangat baik menunjukan persentase sebanyak $6 \%$, kategori baik menunjukan persentase sebanyak 37\%, kategori cukup baik menunjukan sebanyak 17\%, kategori buruk menunjukan sebanyak 13\%, dan kategori sangat buruk menunjukan 27\%. Sehingga dapat disimpulkan bahwa pandangan atau persepsi pengunjung tentang lokasi sarana dikategorikan baik.

\section{4) Deskripsi Indikator Mutu Sarana}

Berikut berlandaskan hasil pengolahan data statistik dapat dilihat pada tabel 5 :

Tabel 5. Deskripsi Indikator Mutu Sarana

\begin{tabular}{|c|c|c|c|}
\hline Kategori & Rentang Skor & F & \% \\
\hline Sangat Baik & $\geq 19,995$ & 1 & $1 \%$ \\
\hline Baik & $16,665-<19,995$ & 6 & $6 \%$ \\
\hline Cukup Baik & $13,355-<16,665$ & 39 & $39 \%$ \\
\hline Buruk & $10,005-<13,335$ & 24 & $24 \%$ \\
\hline Sangat Buruk & $<10,005$ & 30 & $30 \%$ \\
\hline \multicolumn{2}{|r|}{ Jumlah } & $\mathbf{1 0 0}$ & $\mathbf{1 0 0 \%}$ \\
\hline
\end{tabular}

Dari hasil pada tabel diatas dijelaskan bahwa persepsi pengunjung tentang mutu sarana dapat dikategorikan sebagai berikut: kategori sangat baik menunjukan persentase sebanyak $1 \%$, kategori baik menunjukan persentase sebanyak $6 \%$, kategori cukup baik menunjukan sebanyak 39\%, kategori buruk menunjukan sebanyak 24\%, dan kategori sangat buruk menunjukan $30 \%$. Sehingga dapat disimpulkan bahwa pandangan atau persepsi pengunjung tentang mutu sarana dikategorikan cukup baik.

\section{B. Pembahasan}

Dapat dijelaskan bahwa hasil dari penyebaran kuesioner dengan 21 pernyataan yang dibagikan kepada 100 responden dapat dikategorikan cukup baik dengan persentase 53\% berada pada rentang skor 52,67 $-<73,33$. Sehingga berlandaskan hasil data diatas dapat kita lihat bahwa daya tarik TWA Rimbo Panti Kabupaten Pasaman sudah cukup memenuhi harapan pengunjung yang datang. Sarana merupakan segala sesuatu yang dirancang guna menyediakan keperluan wisatawan yang tinggal selagi di tempat wisata, sehingga dapat tenang dalam mengikuti aktivitas yang disediakan [6]. Oleh karena itu diharapkan pengelola harus meningkatkan sarana yang ada agar dapat mencapai kategori sangat baik sehingga membuat wisatawan lebih nyaman berada di daya tarik wisata. Berikut persepsi pengunjung tentang sarana di TWA Rimbo Panti di tinjau dari indikator bentuk sarana, fungsi sarana, lokasi sarana dan mutu sarana.

\section{Indikator Bentuk Sarana}

Persepsi pengunjung tentang sarana di daya tarik TWA Rimbo Panti Kabupaten Pasaman yang ditinjau dari indikator bentuk sarana yang menunjukan kategorikan baik dengan interpretasi persentase $34 \%$ yang berada pada rentang skor 16,665 - <19,995. Bentuk Sarana memiliki arti bahwa suatu bentuk fasilitas haruslah yang mudah dilihat dan dikenali oleh wisatawan [7]. berlandaskan teori diatas menunjukan bahwa yang menjadi tujuan wisatawan berkunjung ke suatu daya tarik wisata adalah bentuk sarana yang dimilikinya, sehingga bisa kita lihat bahwa persepsi pengunjung tentang sarana di daya Tarik wisata TWA Rimbo Panti yang ditinjau dari indikator bentuk sarana sudah memberikan pandangan yang baik sesuai dengan harapan pengunjung yang datang. 


\section{Indikator Fungsi Sarana}

Persepsi pengunjung tentang sarana di daya Tarik wisata TWA Rimbo Panti Kabupaten Pasaman yang ditinjau dari indikator fungsi sarana dapat dikategorikan cukup baik dengan persentase 37\% yang berada pada rentang skor $16-<20$. Fungsi sarana artinya sarana yang tersedia harus berfungsi dengan baik [7]. Oleh karena itu perlu untuk melengkapi perlengkapan dan perbaikan sarana agar sarana dapat digunakan oleh pengunjung sebagaimana mestinya, sehingga persepsi pengunjung bisa mencapai kategori sangat baik.

\section{Indikator Lokasi Sarana}

Persepsi pengunjung tentang sarana di daya Tarik wisata TWA Rimbo Panti Kabupaten Pasaman yang ditinjau dari indikator lokasi sarana dikategorikan cukup baik dengan persentase $37 \%$ yang berada pada rentang skor 16,665-< 19,995. Dalam hal ini dapat kita lihat bahwa persepsi pengunjung tentang lokasi sarana di daya tarik TWA Rimbo Panti cukup baik sesuai dengan harapan pengunjung yang datang berkunjung. Lokasi sarana mempunyai arti yaitu lokasi suatu sarana harus mudah ditemukan dan tidak membingungkan pengunjung [7]. Maka dengan adanya lokasi sarana yang strategis pada sebuah daya tarik wisata dapat memberikan kemudahan bagi pengunjung.

\section{Indikator Mutu Sarana}

Persepsi pengunjung tentang sarana di daya tarik wisata TWA Rimbo Panti Kabupaten Pasaman yang ditinjau dari indikator mutu sarana menunjukan kategori cukup baik dengan persentase penilaian responden $39 \%$ yang berada pada rentang skor 13,355 -<16,665. Dalam hal ini bisa kita lihat bahwa persepsi pengunjung tentang mutu sarana sudah memberikan pandangan yang cukup baik sesuai dengan harapan pengunjung yang datang. Mutu sarana artinya kualitas suatu sarana harus diperhatikan mulai dari bahan yang digunakan serta kondisi sarana tersebut [7]. Mutu sarana dilihat dari bahan yang digunakan untuk membuat sarana dan terpenting kepada kondisinya. Misalnya dinding mushalla yang dicat dengan baik dan kebersihan toilet. Sarana yang baik akan mampu menarik minat pengunjung untuk datang ke suatu daya Tarik wisata dan diharapkan dapat meningkatkan pendapatan masyarakat di sekitar daya Tarik wisata tersebut [8].

\section{KESIMPULAN}

Secara umum dapat dilihat bahwa Persepsi Pengunjung Tentang Sarana di Daya Tarik Taman Wisata Alam Rimbo Panti dapat dikategorikan cukup baik dengan persentase 53\% yang berada pada rentang skor 52,67 $-<73,33$. Maka dapat dijelaskan persepsi pengunjung tentang sarana di daya Tarik wisata TWA Rimbo Panti ke dalam 4 indikator sarana berikut ini :

1. berlandaskan indikator bentuk sarana dapat dikategorikan baik dengan persentase $34 \%$ yang berada pada rentang skor $16,665-<19,995$.

2. berlandaskan indikator fungsi sarana dapat di kategorikan cukup baik dengan persentase $37 \%$ yang berada pada rentang skor $16-<20$.

3. berlandaskan indikator lokasi sarana dapat di kategorikan baik dengan persentase $37 \%$ berada pada rentang skor $16,665-<19,995$.

4. berlandaskan indikator mutu sarana dapat di kategorikan cukup baik dengan persentase $39 \%$ berada pada rentang skor 13,355 $-<16,665$. 


\section{DAFTAR PUSTAKA}

[1] Pemererintah Indonesia 2009, "Undang-Undang Dasar Nomor 10 tahun 2009 tentang Kepariwisataan Pemerintah Pusat, Jakarta," 2009.

[2] P. I. 1990, "UU No. 5 Tahun 1990 Tentang Konservasi Sumberdaya Alam Hayati," no. 5, 1990.

[3] V. dan I. M. C. Ananda, "PERSEPSI PENGUNJUNG TENTANG SARANA DAN PRASARANA OBJEK WISATA RUMAH POHON TABEK PATAH,” vol. 2, pp. 2-9, 2020.

[4] Devola Martania Fentri, "PERSEPSI PENGUNJUNG TERHADAP DAYA TARIK TAMAN WISATA ALAM HUTAN RIMBO TUJUH DANAU DI DESA WISATA BULUH CINA KECAMATAN SIAK HULU KABUPATEN KAMPAR RIAU," Dep. Adm. \pm Tour. Stud. Progr. Fac. Soc. Polit. Sci. Riau Univ., vol. 4, no. 2, pp. 1-11, 2017.

[5] Sugiyono, Metode Penelitian Kuantitatif, Kualitatif, dan R\&D. Bandung : Alfabeta. 2018.

[6] L. Nasution, S. Anom, and A. Karim, "Pengaruh Program Sapta Pesona Dan Fasilitas Terhadaptingkat Kunjungan Objek Wisata T-Gardendi Kecamatan Deli Tua Kabupaten Deli Serdang," J. Darma Agung, vol. 28, no. 2, p. 211, 2020, doi: 10.46930/ojsuda.v28i2.627.

[7] W. Marvidola, Triska, Kasmita, "PERSEPSI WISATAWAN TENTANG PROMOSI DAN FASILITAS OBJEK WISATA MUSEUM ADITYAWARMAN DI KOTA PADANG," no. September, 2014.

[8] V. Ananda and I. Meirina, "PERSEPSI PENGUNJUNG TENTANG SARANA DAN PRASARANA OBJEK WISATA RUMAH POHON TABEK PATAH," Kaji. Pariwisata dan Bisnis, vol. 1, no. 2, pp. 88-95, 2020, doi: https://doi.org/10.24036/jkpbp.v1i2.8272. 